\title{
NUCLEI AND SEX
}

\author{
By William M. Davidson and D. Robertson Smith \\ Department of Clinical Pathology, King's College Hospital, London
}

Before embarking upon the problem of sex determination it is necessary to realize that the very definition of sex is difficult. The Oxford Dictionary defines the male as the one who begets and the female as the one who bears children. This obviously has a limited application, for, amongst other things, a distinction between the sexes in childhood would be impossible.

Anyhow, the simple social separation of human beings into two definite categories, male and female, does not quite agree with the medical conception which allows for morphological misfits between the sexes. The problem of these misfits, sometimes confused with aberrations of behaviour, such as transvestitism and homosexuality, has led to a considerable amount of legal strife and sensational publicity. Rather like the one lost sheep, it might seem that thus the occasional intersex has obtained more attention than the frequency of the condition should warrant, but it is believed that as many as I per $I, 000$ persons are affected (Young, 1937). These malformations of the genitalia, although sometimes a source of considerable social embarrassment to the unfortunate individual, do provide natural experiments in embryology and their inzestigation has revealed intriguing scientific problems.

Though almost all these intersexes are sterile, they are too diverse a group to suggest a ' neutral sex,' for, apart from the very rare true hermaphrodites, only 74 in the literature (Overzier, 1955), they do not lie 'midway between the sexes,' but form a spectrum of individual types ranging from one sex to the other.

The suggestion that the sex of an individual should be decided by the gonads present (Armstrong, 1953) is also incomplete and difficulty arises with individuals apparently of male or female phenotype; that is, as regards body configuration, external genitals and psychological outlook, but who nevertheless have gonads of the opposite sex. Although not the whole answer, this gonadal method has advantages and is used as the basis of the Klebs classification of intersexes into male pseudo-hermaphrodites, true hermaphrodites with both testes and ovaries and female pseudô hermaphrodites.

Since Painter (1924) demonstrated the XY male and XX female chromosome structure it seem agreed that sex is genetically determined, and theres fore scientifically the sex of an individual shour be based upon the genotype. Although it theoretically possible to establish the geneticap sex from analysis of mitotic figures in the spermato gonia-and it has been done in male intersex cases (Greene et al., I952 and 1954; Severinghaus, 19420b - the technique is very difficult and the resulto hard to interpret (Greene et al., I954). The tissue culture method developed by Hsu (1952) is mine practical, but still requires special facilities considerable experience in chromosome study. $\frac{\mathbb{D}}{3}$

In the past few years a number of methods hive been developed, making it possible to recognize $\frac{}{2}$ sex difference in resting (inter-mitotic) nuce्eip Although chronologically not the first, Hydể (1952) recognition by means of ultra-violet light photography of a sex difference in resting nucle in the rabbit should come first. This was the logical outcome of the work started with Geitler (1937) demonstration that the female chromosomo in the water skater (Gerris lateralis) could be fol lowed into the resting nucleus on account of thê large amount of deeply staining chromatin it con? tributed. The intermediate step was provided b Caspersson and Schultz (1940), who, using ultra: violet light, demonstrated a nuclear difference i⿱ the female of the fruit fly, Drosophila.

At this point workers in wholly unrelated fields were by accident drawn into the problem. $\bar{t}$. could never have been anticipated that Professo on Barr, of London, Canada, an experimental neurohistologist, would stumble upon a morphologica sex difference in the resting nucleus while studyin chromatolysis in the hypoglossal neurons of the. female cat (Barr and Bertram, 1949). With exquisiţ technique he noticed in a number of experiments that a prominent chromatin mass about $I \mu$ i diameter moved away from the nucleolus as result of stimulation of the nerve. Subsequentl产 the mass could not be demonstrated in male cats 

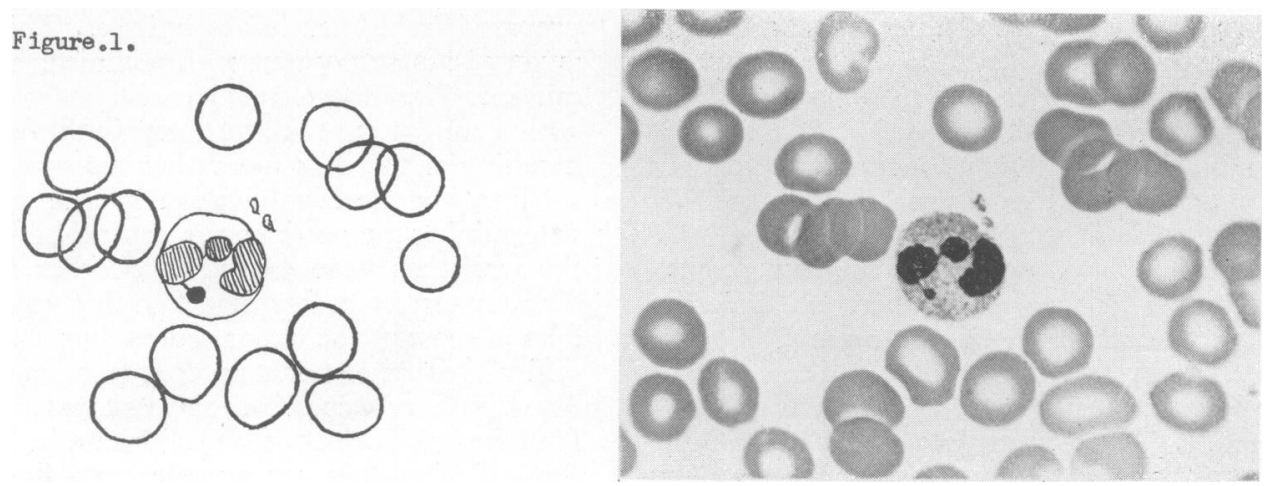

The typical chromatin nodule in a neutrophil leucocyte in the female. The nodule illustrated is I. $4 \mu$ in diameter, while neighbouring red blood cells measured on the average $7.3 \mu$. Coverslip preparation. Jenner Giemsa stain. $\times$ I,200.

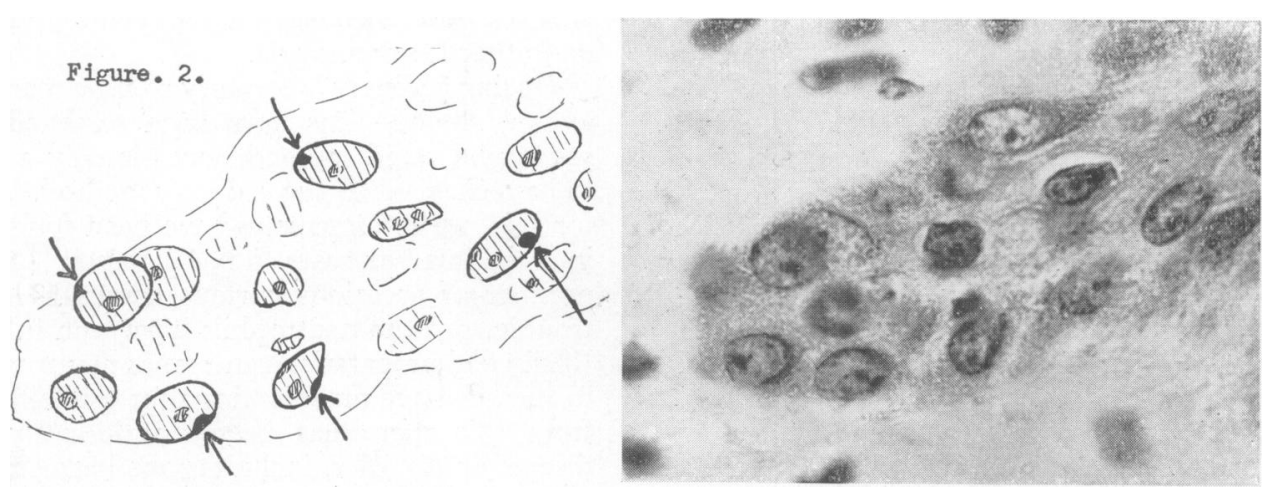

The typical nodules in the nuclei of the epithelial cells of the skin. An average nodule measures r.6 $\times 0.9 \mu$, while red cells in a neighbouring blood vessel measured on the average $5.6 \mu$. The change in the red cell diameter can be accounted for by the different method of preparation. These measurements are slightly greater than those given by Barr (1955) and Emery (I 954), but, allowing for the magnification, the nodules in their photographs are comparable in size to those illustrated here. Section. Haematoxylin and eosin stain. $\times \mathbf{1}, 200$.

The observation of a sex difference in the neurons was rapidly confirmed and extended to other tissues and other mammals, including man (Moore et al., 1953; Barr, I954; Moore and Barr, 1953 and 1954). Using skin biopsies, the method has been developed into a reliable technique for assessing what is believed to be the genetic sex. Barr's findings have been amply confirmed by a considerable number of workers, including Emery and McMillan (1954) and Hunter et al. (1954), and a large literature is now accumulating.

More recently the difficulty of a biopsy has been overcome by examining cells scraped from the buccal mucosa (Moore and Barr, I955a) or from the vaginal wall (Carpentier et al., 1955) and by a particular application the sex of the unborn child can be determined from cells desquamated into the amniotic fluid (James, 1956). The feature which distinguishes the female epithelial cell is a small chromatin nodule which stains deeply with haematoxylin and eosin and can be shown by the Feulgen technique to consist of desoxyribonucleic acid. This nodule, about $\mathrm{I} \mu$ in diameter, is present in some 75 per cent. of female cell nuclei and often lies close to the inner surface of the nuclear membrane (Fig. 2). In the male a similar or rather smaller chromatin nodule may be found in under Io per cent. of the nuclei. The essential points of the various techniques are reviewed by $\operatorname{Barr}\left(1955^{\mathrm{b}}\right)$ and Lennox (1956), who emphasize the importance of good technical methods and particularly the immediate fixation of smears.

While investigating the reason for the arrest of the neutrophil lobing in the Pelger Hüet anomaly (Davidson et al., I954), minor projections and tags arising from the nuclei of many normal neutrophils, 
but not seen in the Pelger cells, became a source of interest. A reference to one of Barr's earlier papers describing his intra-nuclear sex nodules as nuclear ' appendages' undoubtedly played a part in calling attention to the fact that a distinctive type of ' appendage,' shaped like a drumstick, occurred only in the female neutrophil leucocytes.

In a considerable proportion of the neutrophils and eosinophils in the female there are heterochromatin nodules which stain deeply not only by the Romanowsky stains, but also by the haemotoxylin and eosin, methyl green pyronin and Feulgen methods. These sessile nodules, although muc $>$ more frequent and usually larger, may be difficult to distinguish from nuclear thickenings occasionally found in the male. It appears that in the female some of these nodules become pedunculated and form the characteristic female drumsticks (Davidson and Smith, 1954). These have a deeply staining chromatin head some I.4 to $1.6 \mu$ in diameter attached to the rest of the nucleus by a filamentous neck (Fig. I). The frequency with which they occur depends to a great extent upon the degree of lobing of the neutrophils, being unknown in the Pelger Hüet anomaly and other extreme shifts to the left, very frequent in shifts to the right, as in untreated pernicious anaemia, and present in films with an Arneth count of nearly three lobes per neutrophil in something of the order of every thirtieth cell. For statistical purposes the discipline of finding six such drumsticks to obtain the interval between five has been used and is probably well worth adhering to in cases of doubtful sex.

As with the skin biopsy or mucosal scraping methods, the blood cell preparations must be of the highest quality to avoid errors. During the process of smearing blood on slides it would seem that some of the neutrophils are damaged, particularly at the edges of the preparations. As a result trivial nodules under $\mathrm{r} .4 \mu$ in diameter become squashed and even chromatin puffs may be extruded from the nucleus to form structures which may be mistaken for the real drumsticks. Only coverslip preparations made by allowing the blood to spread by capillary attraction (Wintrobe, I95I) should be used. Difficulties have arisen several times when smears on slides were used and it cannot be agreed that they are equal to coverslip preparations, as Sun and Rakoff (1956) have suggested. The film must be stained precisely, as Lennox (1956) has pointed out for epithelial cells. There should be no suggestion of diffuseness of the stain and the nuclear membrane should appear as a series of elongated chromatin masses fencing in the rest of the nuclear chromatin. The examination can be facilitated by taking venous blood and making coverslip films from a leucocyte cream prepared by a 'gentle' technique. This methog is very satisfactory and with technical help muef quicker. Kosenow (1956) has also had good resuls with a similar method, but one would fear lest his handling of the cells was rather too severe.

Since the first publication of the method of determining the sex from the neutrophil leucocytes the work has been extended to other mammaks The sex can be differentiated in this way in men bers of most of the major orders, but considerab difficulty has been encountered in certain specie $\stackrel{p}{s}$. A preliminary account of this work was given to the Pathological Society of Great Britain in July 195\$. Several of species not sexable from the ganglion cells (Moore and Barr, 1953) have been found to be sexable from the neutrophils. The rabbif proved to be almost as easy as the human being, an observation confirmed by Thea Lüers (1956).

A sex difference has not yet been found in bir. and other lower animals.

During ordinary laboratory routine many thous ands of blood films have been screened for the sex by 'a rapid method,' occasionally a film his to be rechecked by the ordinary method. Allowirg for this, no discrepancies have been found except in some intersex cases to be discussed later. Qn-a number of occasions curious names have carseg trouble, but the neutrophils have won in the Really bad preparations and gross neutrophil shifts to the left have made sexing impossible, but apast from this there has been no difficulty in any disease or disorder, including the leukaemias. of

In addition to the neutrophils, the eosinophifis are relatively easy to sex, but nodules have beefl observed too infrequently in the basophils to make any decision possible. Monocytes may well sexable from an intranuclear mass comparable that seen in epithelial cells, but unexplained dis crepancies have been found. The lymphocytes have not been found to be different in the two sexes.

Sexing of the neutrophils has now become a we established method and with experience the pitfail of ' false nodules' can be eliminated. Showt methods are not yet advisable (Lüers, 195\%; Wiedemann et al., I955), but a formula including the other small nodules (Kosenow, 1956) seems क्षी unnecessary complication. The original observa tion of the neutrophil sex difference has been confirmed by a number of authors (including Tolks dorf et al., 1955; Kosenow and Scupin, r95 Riis, 1955; Polani and Magnus, 1955; Lüers; 1956; Sun and Rakoff, 1956; and Briggs arte Kupperman, 1955). In quite a number of cases the epithelial cell method and the leucocyte method have been compared and shown to agree (Polagi and Magnus, 1955).

The various methods of sexing individuals from 
the nuclear structure must be regarded as complementary and the particular one chosen should depend upon the experience of the investigator. Undoubtedly any of these methods, although apparently simple, must be performed by a person fully trained in microscopy and at best only discredit can result from the efforts of the dilettante. Probably it is wise to use two separate methods in the investigation of any difficult case.

The application of nuclear sexing to the problem of intersex has both clarified and complicated the issues. It seems that in intersexes the formation of the genitalia, the direction of the psychological outlook, the weighting of the hormonal balance, the type of gonad present and the genetic sex as deduced from the nuclear structure can disagree in a complexity of ways. It is probably best to regard the genetic sex as the background upon which the picture leading to the phenotype is built up. It cannot be emphasized too strongly that when the phenotype and the genotype are at variance, particularly in adults, it is almost invariably best to assign the patient to the sex corresponding to the phenotype and deposit the information regarding the true genetic sex in the deepest recess of an absolutely private scientific file. For this reason it is preferable to call the finding of typical chromatin nodules, as in the normal female, 'chrom tin positive' and the lack of these ' chromatin negative' (Barr, I956a and b). Nuclear sexing is perhaps most useful in helping to separate the more basic ' genetico-sexual ' upsets from those of a purely psychological nature, such as transvestitism (Barr and Hobbs, 1954), and thereby ensuring that the sufferer is offered the appropriate form of treatment. In investigating a definite intersex nuclear sexing is not merely a research tool, but provides information regarding the genotype, and should take its place along with the other established forms of examination necessary to fit the case into one of the recognized groups (Wilkins et al., 1955).

With all the information available the decision regarding the correct sex group into which to put an intersex is then made with care and consideration. It must never be a snap decision before operating. In infancy the genetic sex carries more weight than in adults where the configuration of the external genitals and the upbringing are of greater importance (Hampson et al., 1956). Having made the decision the question of remoulding the external genitals to aid the patient in fitting into the chosen sex may be considered. These operations should be viewed conservatively (Browne, I955), particularly if they involve castration, for the gonads may be producing the hormones which keep the patient in balance, even if they do not appear to fit the phenotype or the sex to which the patient has been assigned (Chapple, 1937).

Nuclear sexing is particularly useful in the diagnosis of the relatively common adreno-genital type of pseudo-hermaphroditism in children (Barr, 1954, 1955b and 1956b) where a definitely raised I 7-ketosteroid excretion is not to be expected (Hoffmann et al., 1955) and an early decision regarding upbringing and possibly hormonal treatment is important.

In true hermaphrodites the experience with nuclear sexing is still very limited. Thirteen have been examined (Barr, 1955a and c; Tolksdorf et al., I955), and of these nine were chromatin positive and four negative. To this can be added two personal cases, both chromatin positive. In one there was an ovotestis and an ovary (clinical description Capon, I95I), and in the other both ovarian and testicular tissue. The numbers are still too small for any conclusion to be drawn as to the relationship to the bilateral, unilateral or lateral varieties of hermaphroditism. Barr (r955a), presumably including Bromwich's case (Bromwich, 1955), reports that in two lateral cases, testis on one side and ovary on the other, the skin from both sides of the body was of the same chromatin structure; in one case chromatin positive, in the other negative, strong evidence against this being a gynandromorphic state.

All 33 female pseudo-hermaphrodites in the literature with the nuclear chromatin described, including two not of the adreno-genital type, together with personal experience of $I I$, have been chromatin positive (Barr, 1955a; Greenblatt, 1955). In the female pseudo-hermaphrodite in cattle (freemartin) the nuclei are also positive (Moore et al., 1955). Similarly, in 35 cases of male pseudo-hermaphroditism found in the literature, together with personal experience of five, all have been chromatin negative (Barr, 1955a; Swyer, 1955). (The cases listed by Hinglais and Hinglais (1955) were from Barr's series.) In a particular group of eight cases at present being investigated and in blood films sent by Professor Barr from two more (Plunkett and Barr, 1956), chromatin positive nuclei have been associated with male gonads (Klinefelter's syndrome).

The findings in gonadal aplasia (agenesis, dysplasia, Turner's, Bonnavie-Ullrich's or Albricht's syndrome) are very interesting. As with other types of pseudo-hermaphroditism (Schneider et al., 1952), there is strong evidence of a hereditary basis (Reiner and St. Grnja, r955) and blood films from two affected ' sisters' sent by Dr. Overzier, Mainz, help to confirm this. The full syndrome almost invariably occurs in individuals with a female phenotype. They are mainly of short stature, although a tall eunuchoid variation is described 
(Greenblatt et al., 1956), have poorly developed but feminine external genitals, together with a rudimentary uterus, no breast formation, only a very small amount of pubic hair and primary amenorrhoea. A number of other conditions may be associated, particularly coarctation of the aorta, an unusual finding in females. The gonads are characteristic, the 'streak' gonads, silvery white cylindrical structures lying along the Fallopian tubes. On section these prove to consist of undifferentiated stroma lacking either ovarian follicles or testicular tubules, although occasionally mesonephric remains may be found in the inner parts. As these undifferentiated gonads do not act as ' target organs,' the urinary follicle stimulating hormone is usually increased. Some 139 cases have been found in the literature in which the nuclear sex has been determined either from the skin or the neutrophils; there may be a little overlapping, as it appears that some of the cases have been published by other authors in their series (Barr, 1955a; Grumbach et al., 1955). One hundred and sixteen were chromatin negative and 23 chromatin positive. A personal series of I $_{5}$ chromatin positive and three chromatin negative confirms the ratio of five to one. This is an interesting figure which might be taken to indicate that in the heredity of the condition the frequency of the masculizing influence was twice that of and dominant to the feminizing influence, $M M=2$, $\mathrm{MF}=3$, all males, and $\mathrm{FF}=\mathrm{I}$ female, figures roughly similar to those found for the frequency of the genotypes in the Rhesus grouping.

This tendency to feminization of the genital tract has been compared to the experimental findings of Jost (1950) and Raynaud and Frilley (1947), in which destruction of the gonads in the early embryo rabbit or mouse led to a similar feminization. A small group of cases with male external genitals do not appear to be quite the same, as in several there has been testicular tissue (Sougin-Mibashan and Jackson, 1953; Prunty et al., r953; Reiner and St. Grnja, I955); only Tolksdorf et al. (1955) have described absence of testes and a chromatin negative nuclear structure.

That it is possible to sex the resting nuclei is now a well-established fact. What the nodules or drumsticks represent is as yet less well founded, but the ripples spreading out from the large stone thrown into the pond by Barr in 1949 (Lancet leader, 1954) are striking new shores. While there is a great temptation for those engaged in nuclear sexing, be they histologist, cytologist or haematologist, to get caught into the small backwater of the intersexes and lose sight of the widening ripples, fortunately Hunter and Lennox (1954), Moore and Barr (1955b), Moore (1955), Tavares (r955) and Cruickshank (r955) have looked further afield and applied the technique to the sexing off benign and malignant tumours and their hoses. Most have proved to have the same chromation structure, but this does not apply to the teratomati In all those occurring in females the nuclei har been chromatin positive, but 12 of 22 teratomara in males have also been chromatin positive. This discrepancy again raises the question of the origin of these tumours. The fact that no chromation negative tumours have been found in the femate seems to exclude the theory of their representiry an 'included twin.' This leaves the possibility that the male with both the $\mathrm{X}$ and $\mathrm{Y}$ chromosomes available has the potentiality of giving rise to both female (XX) and male (XY) cells. Selक्ष fertilization of the type $(X / Y)(X / Y)$ would produce the ratio of one $X X$ to two $X Y$ to one $Y Y$. Evefy allowing the possibility that $\mathrm{YY}$ is non-viable, this is excluded by the $I: I$ ratio found. Another possibility proposed by Alma Howard (Lennox; 1956) is that an XY cell divides to form a haploid pair X and Y, this followed by chromosomal ret duplication gives a female XX or male YY. third possibility might be that, owing to abnorma division, female cells with the structure $\mathrm{X}$ or XXX might arise with the same frequency as male gells with the structure Y or XYY. These abnorinat chromosomal formations might be expected to 8 is a chromatin nodule of an abnormal size or a drones stick of abnormal structure, but so far this has been reported. In a search for evidence of a tetraploid change in the leucocytes in pernicieus anaemia (La Cour, 1944) many multi-lobed neu phils have been examined for double drumstie but without any success.

Now that the chromatin distribution in the resting nucleus can be related to the sex, the studfy of the nuclear structures may be expected to shed light upon other pairs of chromosomes and eventually to the problems of inheritance. Those interested in the investigation of congenital anomalies should be aware of the methods an their possible applications (Davidson and Ross:1954). Furthermore, the second of Barr's observa tions that the sex chromatin nodule enlarges during: neuron regeneration may be found to provide in 5 formation regarding nuclear activity and metabo $\bar{s}$. ism, and particularly the formation of ribonucleio acid and proteins (Hydén, 1943; Crouch and Barr 1954). Barr's careful investigations are proving to be of fundamental importance.

\section{Summary}

The various methods of determining the nucleart sex are discussed. They appear to be compleo mentary and the method employed should depend upon the circumstances and the preference an $\mathbb{E}$ experience of the observer. Confirmation of the 
findings by two different methods may be advisable in exceptional cases.

The bearing of this nuclear (genetic) sex upon the problems of the intersex is considered. Further applications, particularly to the study of the genesis of teratomatous tumours, are discussed.

\section{BIBLIOGRAPHY}

ARMSTRONG, C. N. (1953), Proc. Roy. Soc. Med., 46, 301. BARR, M. L. (1954), Surg. Gynec. Obstet., 99, 184.

BARR, M. L. (1955a), Anat. Rec., 121, 387 .

BARR, M. L. (1955b), 'The Chromatin and its Application to Errors in Sex Development. Modern Trends in Obstetrics and Gynaecology,' 2nd Ser. Butterworth, London, chap. 7.

BARR, M. L. (1955C) (cited Wilkins et al., 1955).

BARR, M. L. (1956a), Lancet, i, 47.

BARR, M. L. (1956b), Canad. Med. Assn. F., 74, 410.

BARR, M. L., and BERTRAM, E. G. (1949), Nature, Lond., 163. 676.

BARR, M. L., and HOBBS, G. E. (1954), Lancet, i, 1 rog.

BRIGGS, D.' K., and KUPPERMANN, H. S. (1955); Meeting Inter-society Cytol. Council Organization, Ohio, Nov.

BROMWICH, A. F. (1955), Brit. med. F., i, 395

BROWNE, D. (1955), Ibid., i, 1427.

CAPON, A. W. (1951), Lancet, i, 563 .

CARPENTIER, P. J., STOLTE, L. A. M., and VISSCHERS, G. P. (1955), Ibid., ii, 874 .

CASPERSSON, T., and SCHULtTZ, J. (1940), Proc. Nat. Acad. Sci., Wash., 26, 507 (cited Lennox, 1956).

CHAPPL̇ Wash., 26, 507 (cited Lennox, 1956 .

CROUCH, YVONNE F., and BARR, M. L. (1954), f. Neuropath. Exp. Neurol., 13, 353.

CRUICKSHANK, D'. B. (1955), Lancet, i, 253

DAVIDSON, W. M., LAWLER, S. D., and ACKERLEY, A. G.

(1954), Ann. Human Genet., I9,

DAVIDSON, W. M., and ROSS, G.'I. M. (1954), F. Path. Bact., DAVIDS 459 . EMERY, J. L., and MCMILLAN, MARY (1954), f. Path. Bact., 68 , 17.

GEITLER, L. (1937), Ztschr. Zellforsch., 26, 64r.

GREENBLATT, R. B. (I955), Amer. F. Obstet. Gynec., 70, 1165.

GREENBLATT, R. B., CARMONA, N., and HIGDON, L. (I956),

F. Clin. Endocrin.' 16, 235. D., HUGHESDON, P. E., and
GREENE, R., MATTHEWS, D., HU HOWARD, ALMA (1952), Brit. F. Surg., 40, 263.
REENE, R., MATTHEWS, D D. HUGHESDON, P. E., and
HOWARD, ALMA (1954), Ibid., 4I, 548.

GRUMBACH, M. M., VAN WYK, J. J., and WILKINS, L. (1955), Ұ. Clin. Endocrinol., 15, 1161 .

HAMPSON, J. L., and HAMPSON, J. G., and MONEY, J. (1956), Bull. Fohns Hopk. Hosp., 97, 207.

HINGLAIS, H., and HINGLAIS, M. (1955), Pr. Med., 63, 337.

HOFFMANN, F., OVERZIER, C., and UHDE, G. (1955), Geburt. Frauenhk., 15, $106 \mathrm{I}$.
HSU, T. C. (1952), Ұ. Heredit., 43, 167.

HUNTER, W. F., LENNOX, B., and PEARSON, M. G. (1954),

Lancet, i, 372.
HUNTER, W. F., LENNOX, B. (1954), Ibid., ii, 633.

HYDEN, H. (1952), 3 Coll. Ges. Physiol. Chemie, Mosbach., I (cited Lüers, 1956).

HYDEN, H. (1943), Acta. Physiol. Scand., 6, Suppl. 17.

JAMES, F. (1956), Lancet, i, 202.

JOST, A. (1950), Gynec. Obstet., 49, 44 (cited Grumbach, et al., KOSENO). W, W. (1956), Arzt. Wschr., 11, 320

KOSENOW, W., and SCULPIN, S. (1956), Klin. Wschr., 34, $5 \mathrm{x}$.

LA COUR, L. F. (1944), Proc. Roy. Soc., Edinb. (Pt. I, Sect. B),

LEADI, 73. ARTICLE (1954), Lancet, ii, 638.

LENNOX, B. (1956), Scottish Med. Э., 1, 97.

LUERS, THEA (1956), Blut., 2, 81 .

MOORE, K. L. (I955), Anat. Rec., 121, 400.

MOORE, K. L., and BARR, M. L. (1953), f. Comp. Neurol., 98, 213.

MOORE, K. L., and BARR, M. L. (1954), Acta Anat., 21, 179.

MOORE, K. L., and BARR, M. L. (I955a), Lancet, ii, 57.

MOORE, K. L., and BARR, M. L. (1955b), Brit. F. Cancer, 9, 246

MOORE, K. L., GRAHAM, M. A., and BARR, M. L. (I953), Surg. Gynec. Obst., 96, 64I.

MOORE, K. L., GRAḦAM̆, M. A., and BARR, M. L. (1955), Anat. Rec., 121, 442.

OVERZIER C.' (I955) A4ta Endocrinol., $20,63$.

PAINTER, T. S. (I924), Amer. Nat., 58, 506 (cited Severinghaus,

1942).

POLANI, P. E., and MAGNUS, I. A. (1955), Lancet, $i$, I 202.
PRUNTY, F. T. G., MCSWINEY, R. R., CLAYTON, BARBARA E. (1953), F. Clin. Endocrinol., 13, 1480.

RAYNAUD,'A., and FRILLEY,' M. (1947), Acta Endocrinol., Paris, 8, 400.

REINER, L., and ST. GRNJA (1955), Arzt. Wschr., ro, 1039.

RIIS, P. (I955), Danish Med. Bull., 2, I 90.
SCHNEIDER, R. W., VAN OMMEN, R. A., and HOERR, J. J. (1952), F. Clin. Endocrinol., 12, 423.

SEVERINGHAUS, A. E. (1942), Amer. F. Anat., 70, 73 I.

SOUGIN-MIBASHAN, R., and JACKSON, W. P. U. (1953),

Brit. Med. F., ii, 37r.
SUN, LUCILLE. C., and RAKOFF, A. E. (1956), f. Clin. Endocrinol., 16, 55.

SWYER, G. I. M. (1955), Brit. med. F., ii, 709.

TAVARES, A. S. (1955), Lancet, i, 948.

TOLKSDORF, M., ROMATOWSKI, H. SAILE, $M$., and WEIDEMANN, H.-R. (1955), Arzt. Wschr., 10, 1029.

WIEDEMANN, H.-R., ROMATOWSKI, H., and TOLKSDORF, M. (1955), Die Medizinische, Nr., 50, 1734.

WILKINS, L., GRUMBACH, M. M., VAN WYK, J. J., SHEPARD, T. H., and PAPADATOS, C. (1955), Paediatrics, I6, 287.

WINTROBE, M. M. (I95I), 'Clinical Haematology,' 3rd E., London, Kimpton, p. 338 .

YOUNG, H. H. (1937), ' Genital Abnormalities, Hermaphroditism and Related Adrenal Diseases,' Baltimore, Williams and Wilkins (cited Barr, 1955b).

\section{HEPATIC DISEASE}

(Postgraduate Medical Journal, October, 1956)

Price: 3s. 9d. post free

JAUNDICE

Sheila Sherlock, M.D., M.R C.P

HEPATIC COMA

J. M. Walshe, M.A., M.R.C.P.

SURGICAL TREATMENT OF PORTAL HYPERTENSION

A. I. S. Macpherson, Ch M., F.R.C.S.E.

WILSON'S DISEASE

A. G. Bearn, M.D.
ASCITES IN LIVER DISEASE

Michael Atkinson, M.D. (Lond.)

M.R.C.P.

\section{PSYCHIATRIC ASPECTS OF LIVER} DISEASE

Esther A. Davidson, M.R.C.P.Ed., and W. H. J. Summerskill, M.A., M.R.C.P.

PERCUTANEOUS PORTAL VENOGRAPHY

David Sutton, M.D., M.R.C.P., F.F.R.

THE FELLOWSHIP OF POSTGRADUATE MEDICINE 60, Portland Place, London, W.1 